\title{
Assessing public health risk due to extremely high temperature events: climate and social parameters
}

\author{
Luc Vescovi ${ }^{1, *}$, Martine Rebetez ${ }^{2}$, Florian Rong ${ }^{1,2}$ \\ ${ }^{1}$ Ouranos Consortium, 550 Sherbrooke Street West, 19th Floor, Montreal, Quebec H3A 1B9, Canada \\ ${ }^{2}$ WSL Swiss Federal Research Institute, CP 96, 1015 Lausanne, Switzerland
}

\begin{abstract}
The growing recognition of the need to plan institutional responses to the effects of climate change makes it essential to develop research support strategies and tools not only at global but also at regional scales. This paper analyses the feasibility and potential of a risk assessment framework for studies of regional impact of and adaptation to climate change. We assess the potential impact of high temperature events on humans in southern Quebec. We integrate climate variables and socio-economic parameters via a geographic information system (GIS) tool to produce maps of estimated present and future public health risk. A comparison of risk maps for present and future conditions shows that the number of locations where population will be at threat due to high temperature events will dramatically increase in Quebec over the next few decades.
\end{abstract}

KEY WORDS: Public health risk · High temperature events · Southern Quebec

Resale or republication not permitted without written consent of the publisher

\section{INTRODUCTION}

The need to plan for the effects of climate change is becoming urgent for decision-makers in social, economic, and political spheres, as health and human safety problems are expected (McMichael et al. 1996, Smoyer 1998, Kunkel et al. 1999, Barnett 2001, IPCC 2001c, Sparks et al. 2002, Menne et al. 2003, De et al. 2004, Haines \& Patz 2004, McMichael \& Woodruff 2004, Stephenson 2004, Kovats \& Haines 2005). Climate change is expected to modify the frequency, intensity and duration of extreme weather events. As a consequence, more hot days and high temperature events are expected over nearly all land areas (Easterling et al. 2000a,b,c, Barnett 2001, IPCC 2001b, Sparks et al. 2002, Domonkos et al. 2003, Bell et al. 2004, Rebetez 2004, Schaer et al. 2004). National meteorological organizations generally declare heat waves in order to identify stressful events (Keatinge et al. 2000) and to set up operational warning tools. Definitions are based on (1) air temperature thresholds, (2) air temperature thresholds and minimum duration or (3) indices based on a combination of air temperature and relative humidity (Robinson 2001, Koppe et al. 2004). Heat waves are usually defined as occurring when temperatures exceed both daytime high and nighttime low thresholds (Robinson 2001). To justify the involvement of public health stakeholders in special preventive measures (e.g. prolonging opening hours of public swimming pools or air-conditioned shopping centers) the Montreal Public Health Board (MPHB) recently proposed an operational definition based on a daytime high of $30^{\circ} \mathrm{C}\left(T_{\max }\right)$ and nighttime low of $22^{\circ} \mathrm{C}\left(T_{\min }\right)$ for 3 consecutive days (Drouin et al. 2005). These are based on practical definitions. From a thermophysiological point of view, the whole mechanism of heat exchange, including wind velocity and radiation, should be taken into account. In most cases, approximations based on temperature alone prove to be adequate tools (Koppe et al. 2004).

Reducing the adverse impacts of climate change requires both adaptation and mitigation efforts (IPCC 2001a). An adaptative strategy implies an estimate of public health risk (or biophysical vulnerability), i.e. of social vulnerability combined with climate hazard (IPCC 2001a). Adaptive measures require time to put into place. If postponed, some options may be lost forever. Regional and institu- 
tional adaptation actions should be anticipatory and well-planned so as to minimize costs and optimize profitability (IPCC 2001a).

Premature mortality and morbidity are the greatest social costs generated by heat waves in northern temperate countries. Deaths resulting from heat waves in several European, American and Japanese large cities have spurred growing research interest in prevention (Rooney et al. 1995, Semenza et al. 1996, Whitman et al. 1997, Besancenot 2002, Diaz et al. 2002, Curriero 2003, Vanhems et al. 2003, Cassadou et al. 2004, Hemon \& Jougla 2004, Ledrans et al. 2004, Tillaut et al. 2004). High temperature events induce an increase in morbidity, i.e. a decline in health of people affected by cardiovascular, cerebrovascular, and respiratory disorders (McMichael et al. 1996, Haines \& Patz 2004, Hemon \& Jougla 2004, Knowlton et al. 2004, McMichael \& Woodruff 2004). In Canada, climate projections show a significant warming for the future decades (IPCC 2001c). This is of special concern since in cooler regions people are less prepared for heat waves (Ballester et al. 1997, Curriero 2003). Consequently, there could be a significant increase in mortality, particularly among high risk groups such as elderly persons and urban dwellers with low income (IPCC 2001c, Diaz et al. 2002, Sheridan \& Dolney 2003, Davis et al. 2004, Ledrans et al. 2004, Lorente et al. 2004, Tillaut et al. 2004). The strongest correlation factors between impacts of high temperature events on mortality and morbidity and social factors include age (Besancenot 2002, Diaz et al. 2002), poverty (INSERM 2003), social isolation (Besancenot 2002) and education level (Ballester et al. 1997). These factors are often combined and sensitivity rises due to synergetic effects.
We undertake a risk factor analysis for heat waves based on 2 components: climate hazard and social vulnerability. The methodology developed for this study was inspired by the NOAA (1999) vulnerability assessment tutorial, the EPA (1998) Guidelines for Ecological Risk Assessment, Cutter \& Scott (1997), Schiegg (2000) and the Tyndall Research Center's research (Adger et al. 2004).

\section{DATA AND METHODS}

We analyze climate hazard and social vulnerability separately and then synthesize the results using maps.

\subsection{Climate hazard}

To characterize climate hazard we interpolated data from 310 Environment Canada stations in southern Quebec to produce 2 indices:

(1) Mean number of days with $T_{\max }>30^{\circ} \mathrm{C}$, for weather stations with data for at least $16 \mathrm{yr}$ between 1971 and 2000 (272 stations). This index was interpolated using the natural neighbour method.

(2) Mean number of episodes per year with at least 3 consecutive days with $T_{\max }>30^{\circ} \mathrm{C}$ and $T_{\min }>22^{\circ} \mathrm{C}$. These were computed from day-to-day series within the period 1971 to 2000 for the stations with Index 1 higher than $2.5 \mathrm{~d} \mathrm{yr}^{-1}$ (67 stations).

Full data series $(30 \mathrm{yr})$ are available for $40 \%$ of the stations (Fig. 1). More than $25 \mathrm{yr}$ of data are available for 170 stations $(55 \%)$. The density of the stations is highest in the South along the Saint Lawrence River and lowest in the North.

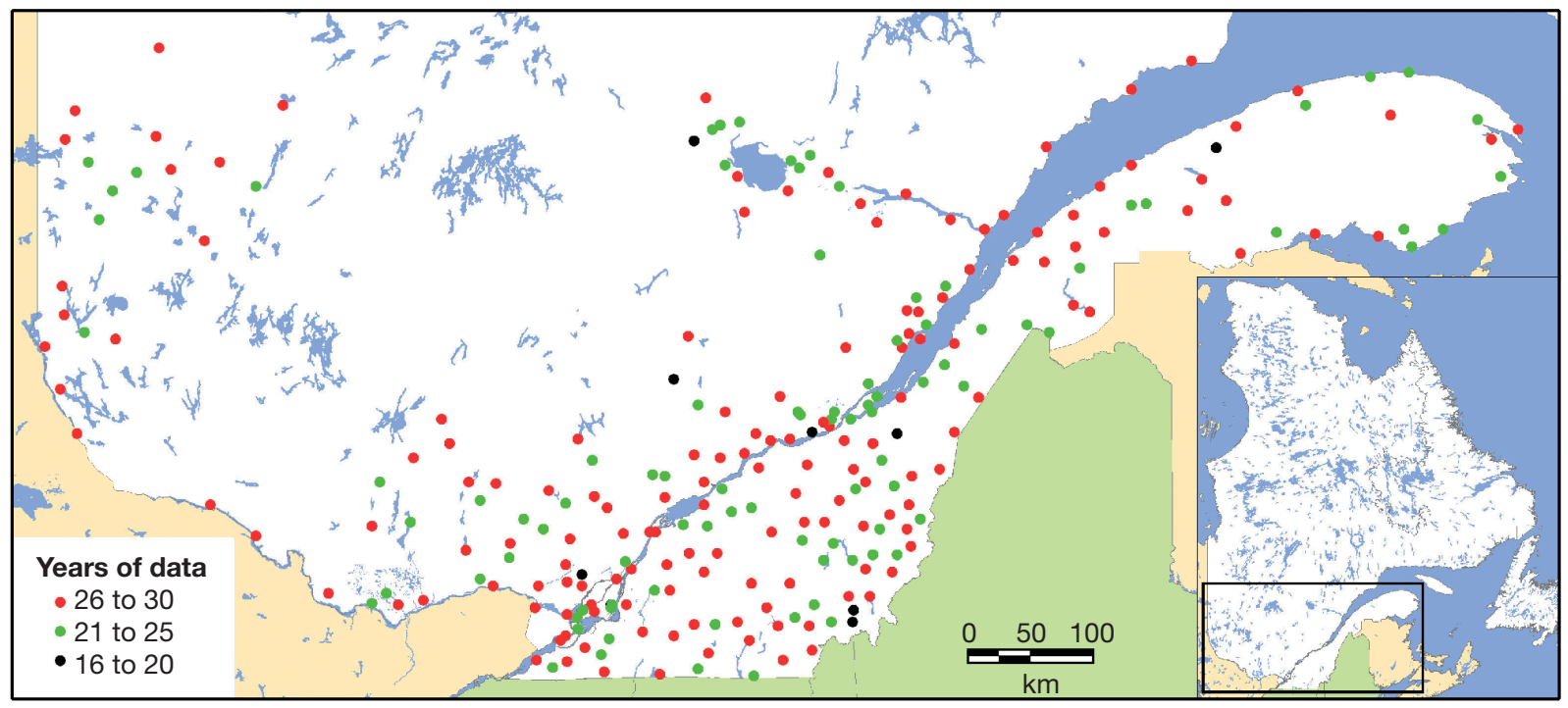

Fig. 1. Meteorological stations in southern Quebec, coded by length of available data series 


\subsection{Social vulnerability}

Social vulnerability was estimated using 4 social subindices expected to be determinant for Quebec's reality. These sub-indices are considered relevant elsewhere for defining humans vulnerable to high temperature events in a temperate climate (Ballester et al. 1997, Besancenot 2002, Diaz et al. 2002). Data originate from the 2001 Canadian population census (Statistics Canada). The geographical unit is the census subdivision (CSD), which corresponds roughly to municipalities.

These 4 social sub-indices are:

(1) Age index: frequency of people older than 65.

(2) Poverty index: frequency of low-income (LICO) earners (LICO-base 2001) as recorded by Statistics Canada for the rural zones, using the FGT (FosterGreer-Thorbecke) index, which classes income in units of 2000 Canadian dollars.

(3) Social isolation index: frequency of single person households.

(4) Education index: frequency of people older than 20 with less than 13 yr of education.

Each social sub-index was centred and the scores were summed. The aggregated social vulnerability index is unitless and ranges between 1 and 8.23. A high social vulnerability is represented by a value of 8.23 , while a value of 1 indicates a low social vulnerability, the mean value being 3.68 .

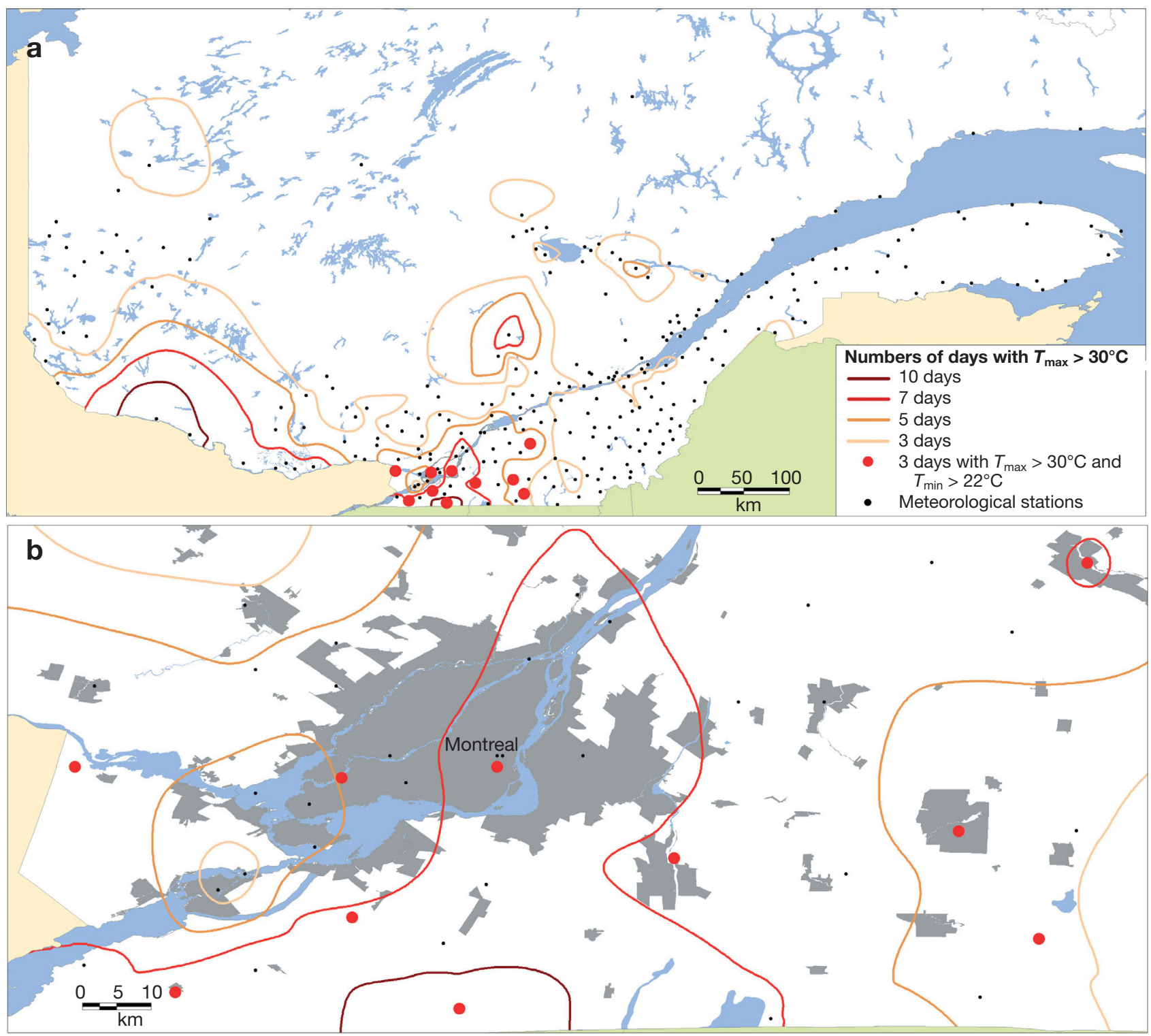

Fig. 2. (a) Contour map of mean number of hot days per year (1971-2000) for southern Quebec. Red dots indicate climate stations reporting heat waves as defined by the climate hazard Index 2 (see 'Data and methods' for details). $T_{\max }$ : maximal daytime temperature; $T_{\min }$ : minimal nighttime temperature. (b) Same as (a), zooming in on the Montreal region (inset from a) 


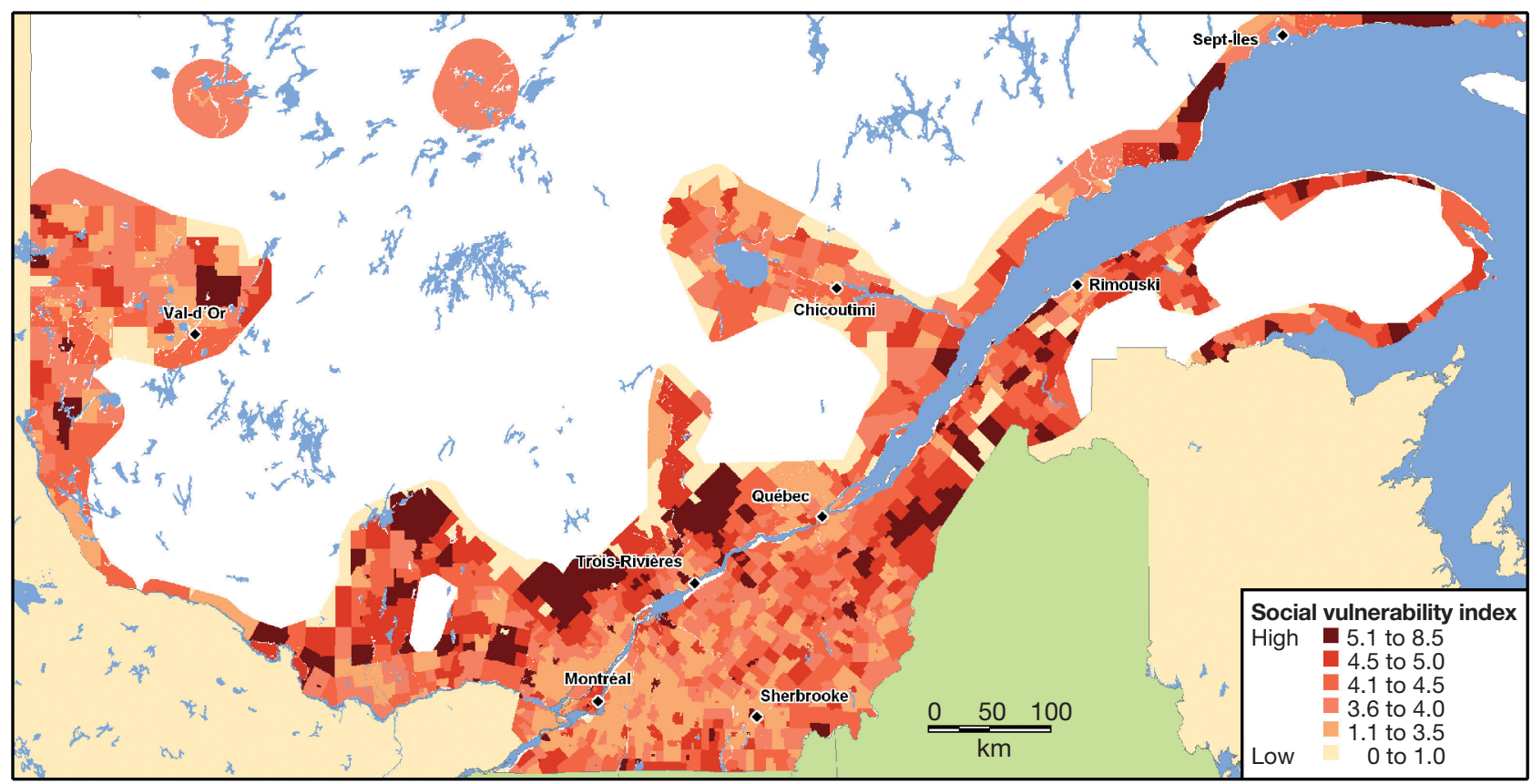

Fig. 3. Map of current social vulnerability based on 4 underlying indicators, i.e. age, poverty, social isolation and education

\subsection{Public health risk assessment}

In order to estimate the present and future potential human impact, climate hazard and social vulnerability were combined using a weighted sum in a geographic information system (GIS). Available demographic data do not enable a detailed projection of each social subindex. However, demographic projections (provided by Statistics Quebec) for 2050 show a general ageing in the province, but no sub-regional distinction could be made. Social conditions are consequently assumed to remain constant and are expected to be somewhat conservative. Climate projections for 2039 to 2063 were made using the Canadian Regional Climate Model (CRCM) V3.6.1, driven by the coupled oceanatmosphere model CGCMII and following the IS92a (Intergovernmental Panel on Climate Change, IPCC) emission scenario for greenhouse gas emissions. The CRCM performs climatic simulations at small scales (distance between each grid point about $45 \mathrm{~km}$ ) with a timestep of $15 \mathrm{~min}$ between integrations.

\section{RESULTS}

The highest value for the climate hazard Index 1 is $14.3 \mathrm{~d}$. Values higher than $10 \mathrm{~d}$ are mainly found in extreme southern Quebec in densely urbanized communities (Fig. 2). Six percent of the investigated territory had at least 7 hot days per year between 1971 and 2000 , and $11 \%$ of the territory had more than 3 hot days per year.

Extremely high temperature events (Index 2) were most commonly recorded in the Montreal area. A high social vulnerability can be found in specific sectors of all regions (Fig. 3), although eastern Montreal appears particularly vulnerable.

Projections (Fig. 4b) show a clear increase in the number of hot days compared to the present situation (Fig. 4a). Approximately $40 \%$ of the investigated territory is expected to experience an increase in the number of hot days.

A risk map (Fig. 5) shows the geographical zones where the public health risk is highest during high temperature events. Compared to present conditions, the map based on future climate scenarios shows a larger territory high risk. The region affected most is the most densely populated area of southern Quebec: Montreal Island and its suburbs as well as the upper St. Lawrence corridor (MontrealQuebec City) and the Outaouais. These regions already experience a high frequency of heat waves and a higher proportion of their population is socially vulnerable.

Fig. 4. (a) Present mean annual number of hot days (maximal daytime temperature $\left[T_{\max }\right]>30^{\circ} \mathrm{C}$ ) based on Canadian Regional Climate Model (CRCM) simulations (under present conditions). (b) Expected mean annual number of hot days $\left(T_{\max }>30^{\circ} \mathrm{C}\right)$ based on CRCM and the Intergovernmental Panel on Climate Change (IPCC) emission scenario IS92a 
a

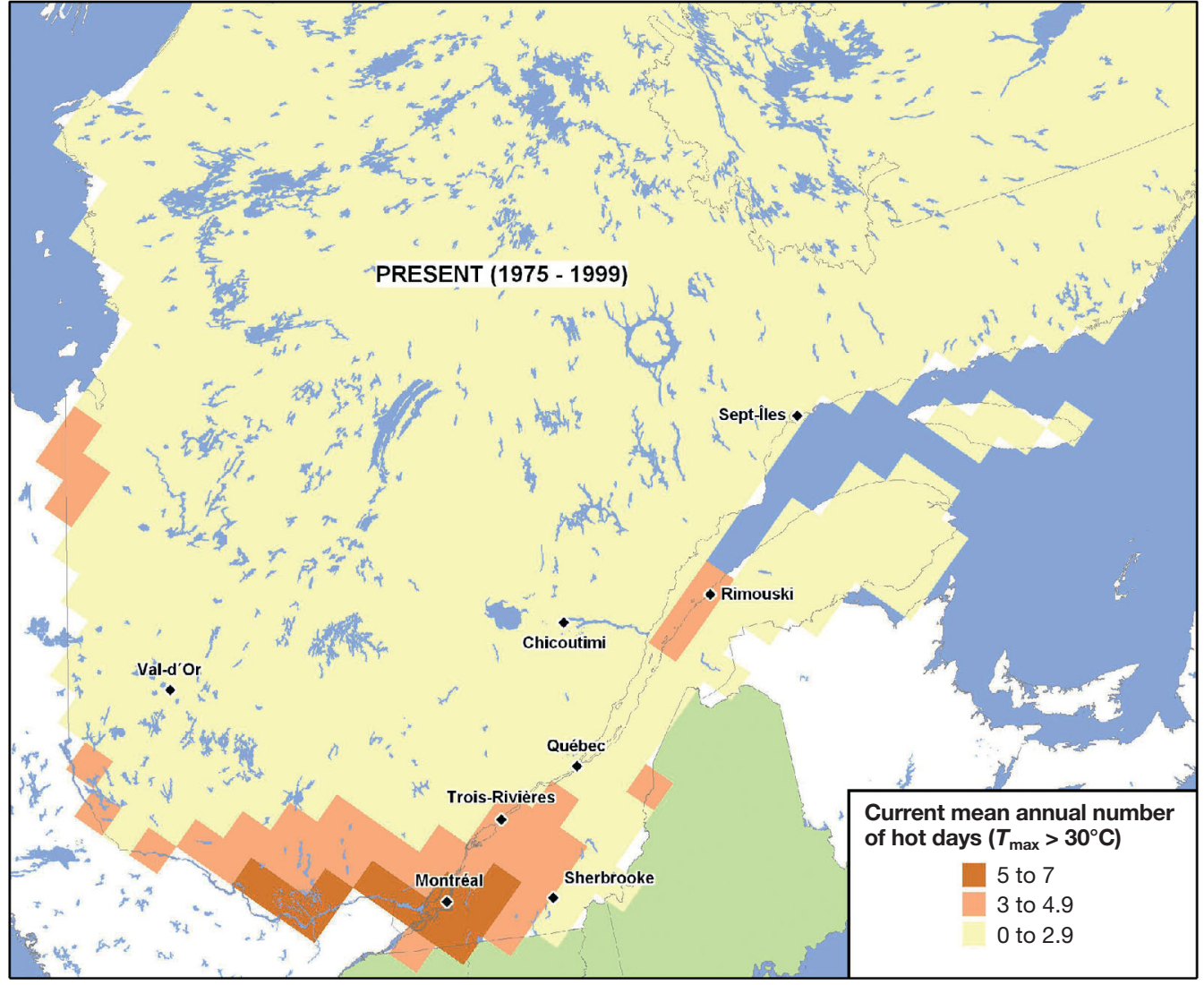

b

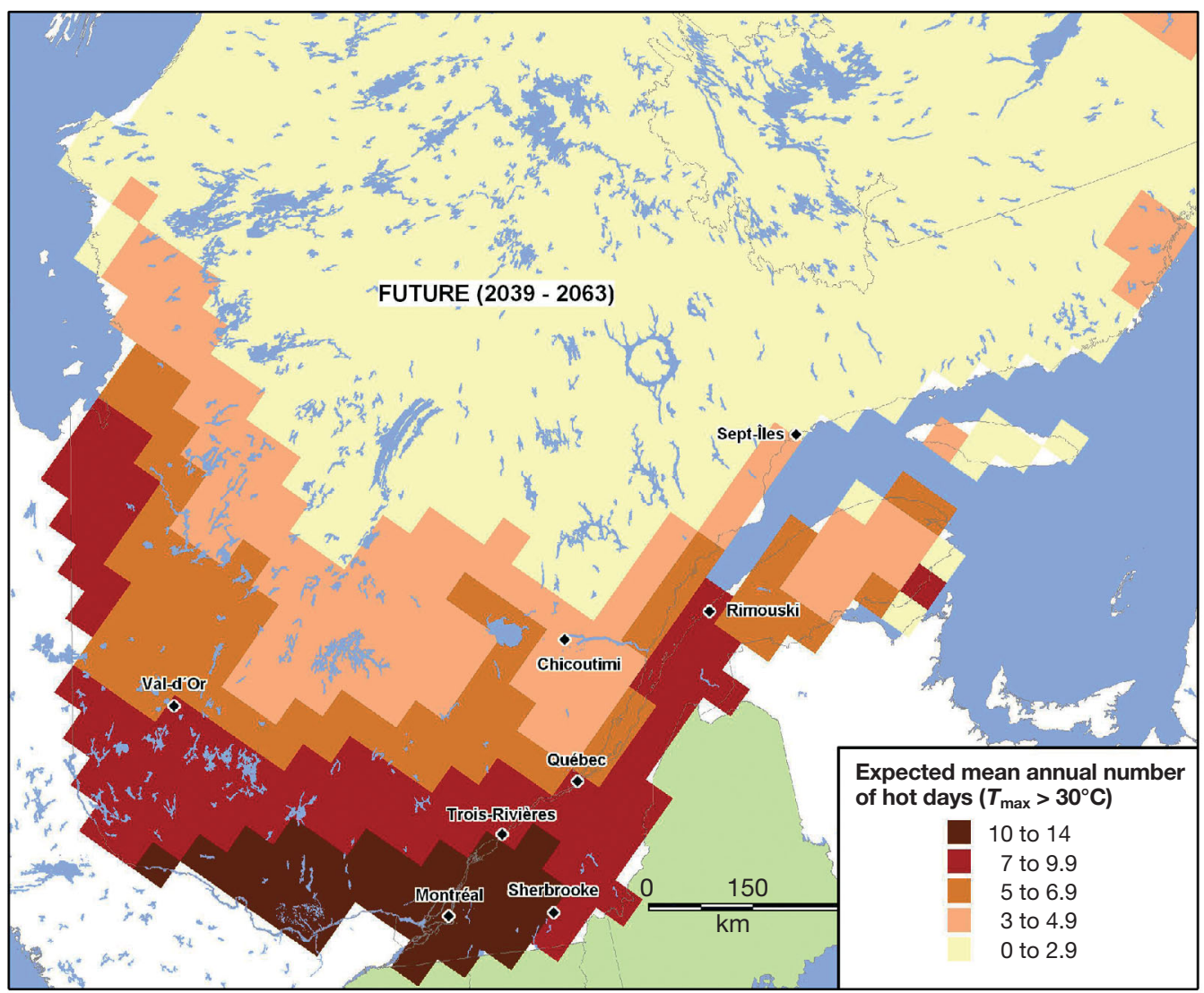




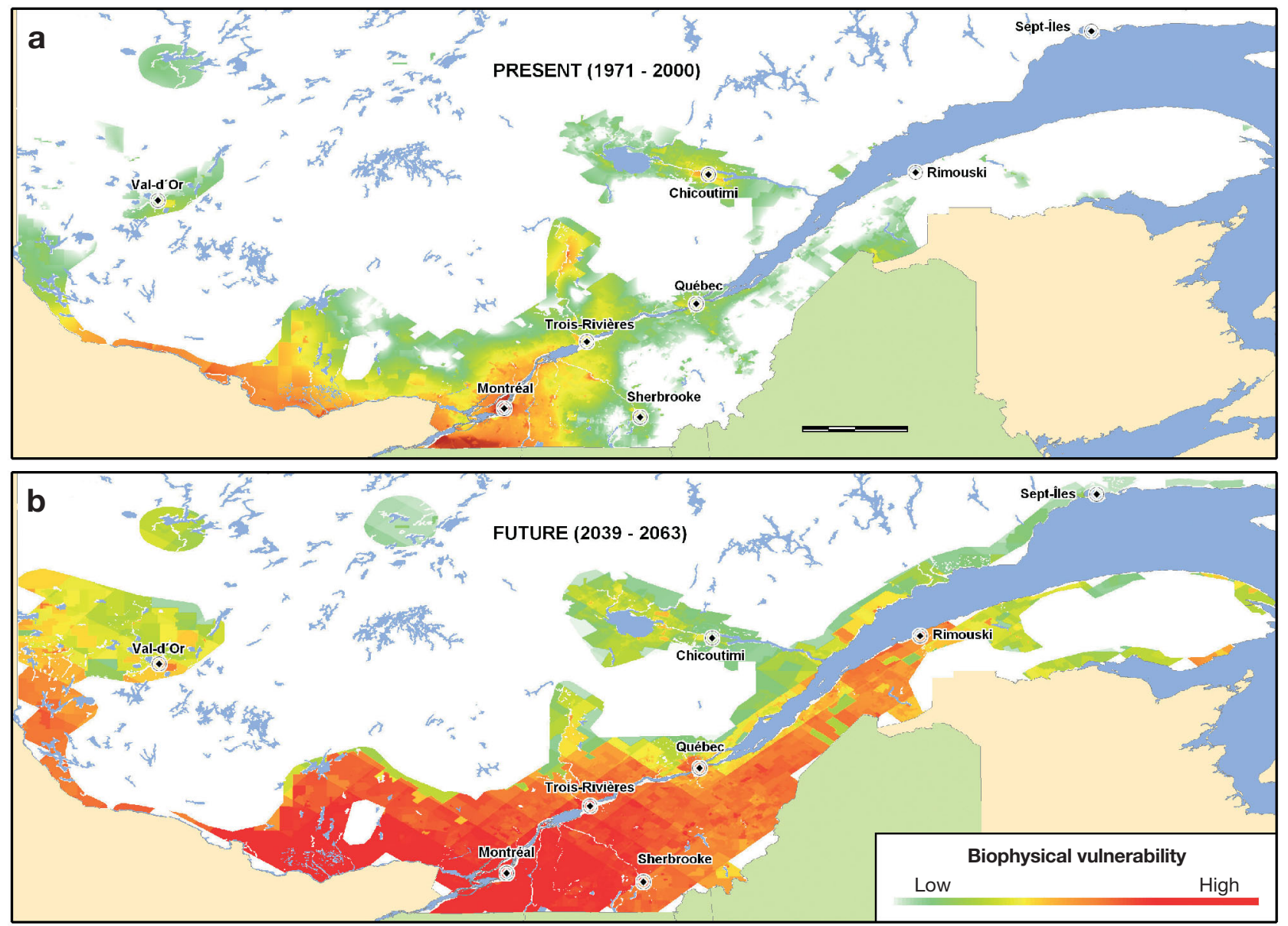

Fig. 5. (a) Present and (b) future public health risk

\section{DISCUSSION}

We expect a strong increase in the number of hot days. This is of course a projection and the most important aspect of our results is the designation of geographic zones with greater future risk due to both the social context and temperature rise.

Our results show that a large number of hot days do not necessarily correspond to uninterrupted heat waves. Hot days may not occur in series, or they may occur when nights (minimum temperatures) are cool. Particularly outside of urban areas, temperatures can be relatively low at night, which has an important positive influence on human comfort and health.

Our analysis relies on basic, widely available quantitative social parameters. As a result, this method can be applied to many other countries in the Northern Hemisphere. A better understanding of the social processes involved could be obtained from an analysis of recent heat wave events such as summer 2003 in Europe. Our method distinguishes the zones where human lives and health are most at risk, not only because humans are present, but because more sensitive groups are present.
Uncertainties in our risk projections are caused mainly by (1) number and type of subcomponents used in the descriptions of social vulnerability, (2) choice of temperature thresholds, (3) interpolation, (4) choice of climate scenarios, (5) integration of human adaptation capacities to a warmer climate.

Including altitude in the climate model could improve the interpolation of results and exclude highaltitude sites from the model of threatened regions. We suggest that the most urgent need is to identify the vulnerable sectors within the Montreal urban area and to set up targeted public health interventions in this region, which already appears to be at risk. Due to the interannual variability in summer temperatures, these zones could be affected by a heat wave at any time, like Europe was, unexpectedly, in summer 2003.

\section{CONCLUSION}

The impact of climate change on public health is of major concern for public health decision-makers and managers in Quebec. This paper demonstrates the 
feasibility and potential of a risk assessment approach and the development of public health risk indices for a regional impact and adaptation climate change study applied to high temperature events.

The assessment of biophysical vulnerability to climate change is a relatively new approach combining physical and human processes. Our results show that social indices can be combined with climate indices to identify sensitive areas at regional scales. Heat waves do not necessarily threaten human populations.

This study gives preliminary input to the Quebec public health decision-makers who intend to develop a spatially explicit on-line analytical processing tool using Web-GIS technology to identify areas vulnerable to climate change.

The most important aspect of our results is the geographical designation of specific zones where people are expected to be at risk in a warmer climate. Specific measures concerning mainly the elderly (Keatinge \& Donaldson 2004) should be put in place for these regions so that relief can be provided immediately in the event of a heat wave.

In order to develop operational indices for high temperature events one needs to consider the local and regional physiological relevance of the thermal environment. The index of biophysical vulnerability we developed is based on easily available climate and socio-economic data. The thresholds of the temperature indices and social parameters have been chosen to tackle existing conditions in southern Quebec. An application of this approach elsewhere using the same values would be feasible for a north-eastern American context (eastern Ontario, upstate New York, western Maine, northern Vermont and New Hampshire), but thresholds would certainly need to be adapted for southern or maritime regions.

Further interpretation should examine the sensitivity of the map to different climate scenarios, temperature thresholds and social parameters. This would allow a better understanding of the weight and importance of each of these parameters and of the different scenarios.

Acknowledgements. This work was supported by Ouranos (financed by the Government of Quebec, Hydro-Quebec and the Meteorological Service of Canada) and by the Forest Investigation Program, a joint project between the Swiss Federal Office of the Environment, Forests and Landscape (BUWAL, Bern) and the Swiss Federal Institute for Forest, Snow and Landscape Research (WSL). We are grateful to Daniel Caya and Helene Cote from the Ouranos Climate Simulations team for providing future climate scenarios and scientific advice regarding $\mathrm{CRCM}$ climate simulations, to Fawziah Gadallah for her useful suggestions and help with the English, and to 3 anonymous reviewers for their useful and constructive comments.

\section{LITERATURE CITED}

Adger WN, Kelly M, Bentham S, Eriksen S (2004) New indicators of vulnerability and adaptive capacity. Report No. 7, Tyndall Center for Climate Change Research, Norwich

Ballester F, Corella D, PerezHoyos S, Saez M, Hervas A (1997) Mortality as a function of temperature. A study in Valencia, Spain, 1991-1993. Int J Epidemiol 26:551-561

Barnett J (2001) Security and climate change. Working paper no. 7. Report No. 7, Tyndall Centre for Climate Change Research, Norwich

Bell JL, Sloan LC, Snyder MA (2004) Regional changes in extreme climatic events: a future climate scenario. J Climate 17:81-87

Besancenot JP (2002) Vagues de chaleur et mortalité dans les grandes agglomérations urbaines. Environnement Risques Santé 1:229-240

Cassadou S, Le Tertre A, Medina S, Eilstein D and 10 others (2004) Excess deaths during the 2003 heat wave in France: which contribution of air pollution? Epidemiology 15:S125-S125

Curriero EA (2003) Temperature and mortality in 11 cities of the eastern United States. Am J Epidemiol 158:93-94

Cutter S, Scott SM (1997) Handbook for conducting a GISbased hazard assessment at the county level. University of South Carolina, Columbia, SC

Davis RE, Knappenberger PC, Michaels PJ, Novicoff WM (2004) Seasonality of climate-human mortality relationships in US cities and impacts of climate change. Clim Res 26:61-76

De US, Khole M, Dandekar MM (2004) Natural hazards associated with meteorological extreme events. Nat Hazards 31:487-497

Diaz J, Garcia R, Velazquez de Castro F, Hernandez E, Lopez C, Otero A (2002) Effects of extremely hot days on people older than 65 years in Seville (Spain) from 1986 to 1997. Int J Biometeorol 46:145-149

Domonkos P, Kysely J, Piotrowicz K, Petrovic P, Likso T (2003) Variability of extreme temperature events in SouthCentral Europe during the 20th century and its relationship with large-scale circulation. Int J Climatol 23: 987-1010

Drouin L, King N, Jacques L, Fortier I, Roy LA, Litvak E, Simard JO, Kosatsky T (2005) The response of the Montreal Public Health Board to climate change: preventing excess morbidity and mortality due to extreme summer temperatures in vulnerable human populations. In: Proceedings of the Conference. Adapting to Climate Change in Canada 2005: Understanding Risks and Building Capacity, Montreal, Québec, 4 to 7 May 2005. Natural Resources Canada's Climate Change Impact and Adaptation Program and the Canadian Climate Impacts and Adaptation Research Network (C-CIARN), p 64

Easterling DR, Evans JL, Groisman PY, Karl TR, Kunkel KE, Ambenje P (2000a) Observed variability and trends in extreme climate events: a brief review. Bull Am Meteorol Soc 81:417-425

Easterling DR, Karl TR, Gallo KP, Robinson DA, Trenberth KE, Dai A (2000b) Observed climate variability and change of relevance to the biosphere. J Geophys Res Atmos 105:20101-20114

Easterling DR, Meehl GA, Parmesan C, Changnon SA, Karl TR, Mearns LO (2000c) Climate extremes: observations, modeling, and impacts. Science 289:2068-2074

EPA (Environmental Protection Agency) (1998) Guidelines for ecological risk assessment. US Environmental Protection Agency, Risk Assessment Forum, Washington, DC 
Haines A, Patz JA (2004) Health effects of climate change. JAMA (J Am Med Assoc) 291:99-103

Hemon D, Jougla E (2004) The heat wave in France in August 2003. Rev Epidemiol Sante Publique 52(1):3-5

INSERM (Institut national de la santét et de la recherche médicale) (2003) Surmortalité liée à la canicule d'août 2003 - estimation de la surmortalité et principales caractéristiques épidémiologiques. INSERM, Paris

IPCC (Intergovernmental Panel on Climate Change) (2001a) Climate change 2001: synthesis report. Summary for Policymakers. IPCC, Geneva

IPCC (Intergovernmental Panel on Climate Change) (2001b) Climate change 2001. The scientific basis. IPCC, Cambridge

IPCC (Intergovernmental Panel on Climate Change) (2001c) The regional impact of climate change. IPCC, Geneva

Keatinge WR, Donaldson GC (2004) The impact of global warming on health and mortality. South Med J 97: 1093-1099

Keatinge WR, Donaldson GC, Cordioli EA, Martinelli M, Kunst AE, Mackenbach JP, Nayha S, Vuori I (2000) Heat related mortality in warm and cold regions of Europe: observational study. Br Med J 321:670-673

Knowlton K, Rosenzweig C, Goldberg R, Lynn B and 10 others (2004) Evaluating global climate change impacts on local health across a diverse urban region. Epidemiology 15(4):S100

Koppe C, Kovats S, Jendritzky G, Menne B (2004) Heat waves - risks and responses. World Health Organization. Regional Office for Europe. Health and Global Environmental Change, Series, No. 2., Copenhagen

Kovats RS, Haines A (2005) Global climate change and health: recent findings and future steps. Can Med Assoc J 172:501-502

Kunkel KE, Pielke RA, Changnon SA (1999) Temporal fluctuations in weather and climate extremes that cause economic and human health impacts: a review. Bull Am Meteorol Soc 80:1077-1098

Ledrans M, Vandentorren S, Bretin P, Zeghnoun A, Maulpoix A, Croisier A, Siberan I, De Clercq B (2004) Heat wave 2003 in France: risk factors for death for elderly living at home. Epidemiology 15:S125-S125

Lorente C, Serazin C, Daube D, Tillaut H, Salines G (2004) Risk factors of mortality during the heat wave of August 2003 in France's nursing homes. Epidemiology 15:S217-S217

McMichael AJ, Woodruff R (2004) Climate change and risk to health. Br Med J 329:1416-1417

McMichael AJ, Haines A, Slooff R, Kovats S (eds) (1996) Cli-

Editorial responsibility: Helmut Mayer,

Freiburg, Germany mate change and human health. An assessment prepared by a task group on behalf of the World Health Organization, the World Meteorological Organization, and the United Nations Environmental Programme. (WHO/EHG/ 96.7) World Health Organization, Geneva

Menne B, Bertollini R, Kovats S, Lindgren E and 14 others (2003) European climate change health impact and adaptation assessment. Epidemiology 14:S116-S116

NOAA Coastal Services Center (1999) Vulnerability assessment tutorial. NOAA Coastal Services Center, Charleston, $\mathrm{NC}$

Rebetez M (2004) Summer 2003 maximum and minimum daily temperatures over a $3300 \mathrm{~m}$ altitudinal range in the Alps. Clim Res 27:45-50

Robinson PJ (2001) On the definition of a heat wave. J Appl Meteorol 40:762-775

Rooney C, Kovats RS, Coleman MP (1995) Excess mortality in England and Wales, and in Greater London, during the 1995 heatwave. Office for National Statistics, London

Schaer C, Vidale PL, Luthi D, Frei C, Haberli C, Liniger MA, Appenzeller C (2004) The role of increasing temperature variability in European summer heatwaves. Nature 427: 332-336

Schiegg O (2000) DRM strategy, sactics, example. World Institutes for Disaster-Risk-Management, Davos

Semenza JC, Falter KH, Selanikio JD, Flanders WD, Howe HL, Wilhelm JL (1996) Heat-related deaths during the July 1995 heat wave in Chicago. N Engl J Med 335:84-90

Sheridan SC, Dolney TJ (2003) Heat, mortality, and level of urbanization: measuring vulnerability across Ohio, USA. Clim Res 24:255-265

Smoyer KE (1998) A comparative analysis of heat waves and associated mortality in St. Louis, Missouri-1980 and 1995. Int J Biometeorol 42:44-50

Sparks J, Changnon D, Starke J (2002) Changes in the frequency of extreme warm-season surface dewpoints in northeastern Illinois: implications for cooling-system design and operation. J Appl Meteorol 41:890-898

Stephenson J (2004) Climate change and health. JAMA (J Am Medl Assoc) 291:291-291

Tillaut H, Salines G, Lorente C, Serazin C, Daube D (2004) Risk factors of mortality during the heat wave of August 2003 in France's nursing homes. Epidemiology 15:S123-S123

Vanhems P, Gambotti L, Fabry J (2003) Excess rate of inhospital death in Lyons, France, during the August 2003 heat wave. N Engl J Med 349:2077-2078

Whitman S, Donoghue ER, Benbow N, Shou W, Mou S (1997) Mortality in Chicago attributed to the July 1995 heat wave. Am J Public Health 87:1515-1518

Submitted: July 1, 2005; Accepted: September 29, 2005

Proofs received from author(s): October 17, 2005 